\title{
PROCESSOAVALIATIVO EM ESTÁGIOS SUPERVISIONADOS: UMA CONTRIBUIÇÃO PARA O ESTUDO
}

\author{
César Cavalcanti da Silva ${ }^{1}$, Ana Tereza Medeiros C. da Silva², Ana Karla Sousa de Oliveira ${ }^{3}$
}

\begin{abstract}
RESUMO: Partindo do pressuposto que o processo avaliativo nos estágios supervisionados encontra-se vinculado a uma abordagem pedagógica tradicional, neste estudo buscou-se compreender o processo avaliativo realizado no estágio supervisionado de um curso de graduaçãoem Enfermagem em atividade no nordeste brasileiro. Os participantes foram quatro enfermeiros, dois supervisores diretos e dois indiretos. A análise do material empírico se deu através da técnica de Análise de Discurso e os resultados evidenciaram que a maioria dos entrevistados utilizava elementos de diferentes abordagens pedagógicas para a prática do processo avaliativo. As contradições observadas relacionaram-se à função dos supervisores diretos e indiretos neste processo, bem como à utilização de abordagens que desconsideram o desenvolvimento crítico, reflexivo e questionador, necessário a uma formação profissional socialmente comprometida. Concluiu-se que há uma urgente necessidade de mudanças no processo avaliativo vigente, a partir do uso de práticas pedagógicas que propiciem uma formação integral ao aluno, superando as vertentes tradicionais, tendo em vista o modelo de saúde vigente e o perfil profissional que ele requer.

PALAVRAS-CHAVE: Educação; Ensino; Enfermagem.
\end{abstract}

\section{EVALUATION PROCESS IN SUPERVISED TRAINING: A CONTRIBUTION FOR THE STUDY}

\begin{abstract}
Assuming that the evaluation process in supervised training is related to a traditional pedagogical approach, this study aimed to understand the evaluation process used in the supervised training of a nursing graduation course in the Brazilian northeastern region. The participants encompassed four nurses, two direct supervisors and two indirect supervisors. The analysis of the empirical material used the technique of Speech Analysis and the results evidenced that the majority of the interviewed used elements of different pedagogical approaches for the practice of the evaluation process. The observed contradictions were related to the function of the direct and indirect supervisors in this process as well as the use of approaches that disregard critical, reflective and inquiring development, necessary to a socially committed professional qualification. It was concluded that there is urgent need of changes in the current evaluation process applying pedagogical practices that foster students' whole education, overcoming traditional trends, keeping in mind the current health model and the required professional profile.
\end{abstract}

KEYWORDS: Education, Teaching, Nursing

\section{PROCESO DE EVALUACIÓN EN PERIODOS SUPERVISADOS DEL ENTRENAMIENTO: UNA CONTRIBUCIÓN PARA EL ESTUDIO}

RESUMEN: Basándose sobre el presupuesto de que el proceso de la evaluación en las prácticas supervisionadas está vinculado a un abordaje pedagógico tradicional, en este estudio se buscó comprender el proceso de evaluación realizado en las prácticas supervisionadas de un curso de graduación en enfermería en actividade en Nordeste brasileño. Los participantes fueron cuatro enfermeros, dos supervisores directos y dos indirectos. El análisis del material empírico ocurrió por medio de la técnica de Análisis de Discurso y los resultados mostraron que la mayoría de los entrevistados utilizava elementos de diferentes abordajes pedagógicos para la práctica de proceso de evaluación. Las contradicciones observadas se relacionaron a la función de los supervisores directos y indirectos en este proceso, así como a la utilización de abordajes que desconsideron el desarrollo crítico, reflexivo y cuestionador, necesario a una formación profesional socialmente comprometida. Se concluyó que hay una urgente necesidad de cambios en el proceso de evaluación vigente acerca del uso de prácticas pedagógicas que propicien una formación integral al alumno, superando las vertentes tradicionales, teniendo en cuenta el modelo de salud vigente y el perfil profesional que este exige.

PALABRAS CLAVE: Educación; Ensenanza; Enfermería.

${ }^{1}$ Enfermeiro. Doutor em Enfermagem. Docente do Departamento de Enfermagem Médico-Cirúrgica e Administração da Universidade Federal da Paraíba - UFPB.

${ }^{2}$ Enfermeira. Doutora em Enfermagem. Docente do Departamento de Enfermagem em Saúde Pública e Psiquiatria da UFPB.

${ }^{3}$ Enfermeira. Graduada pela UFPB.

Autor correspondente:

César Cavalcanti da Silva

Av. Umbuzeiro, 209 - 58038-180 - João Pessoa-PB

Recebido: 11/08/07

E-mail: profccs@yahoo.com.br 


\section{INTRODUÇÃO}

O ensino de Enfermagem no Brasil teve sua origem determinada pela demanda social por cuidados em saúde, adquirindo características próprias de acordo com a época considerada. A prática da Enfermagem no país remonta ao período colonial, quando se caracterizava por fundamentar-se em conhecimentos estritamente empíricos e por se achar sob a égide de ordens religiosas, responsáveis pelo ensino e organização dos serviços de saúde ${ }^{(1)}$.

Nenhuma exigência era feita quanto ao nível de escolarização, esperava-se dos exercentes apenas uma conduta de dedicação, disciplina e obediência, além da capacidade de realizar tarefas domésticas relacionadas à assistência do paciente, bem como limpeza e higiene do ambiente. Esse período representa uma fase pré-profissional da Enfermagem, a qual se estendeu até meados do século XIX, e que se caracterizou pela completa ausência de educação formal dos enfermeiros ${ }^{(2)}$.

A partir de 1890, com a criação da Escola Profissional de Enfermeiros e Enfermeiras, anexa ao Hospital Nacional de Alienados, no Rio de Janeiro, o ensino de Enfermagem foi oficialmente instituído no Brasil, caracterizando-se pela institucionalização da prática, com ênfase na formação hospitalar e subordinação à prática médica ${ }^{(3)}$.

A criação da Associação Nacional de Enfermeiras Diplomadas, atual Associação Brasileira de Enfermagem (ABEn), fez emergir a preocupação com a organização do ensino de Enfermagem no país, especialmente no que concerne ao currículo, o que culminou com sua regulamentação através da Lei ${ }^{\circ}$ $775 / 49$. Inúmeros esforços foram empreendidos à época, no sentido de organizar os cursos de Enfermagem através do estabelecimento de um currículo mínimo que refletisse as necessidades sociais, sempre dando ênfase às práticas curativas em detrimento da prevenção ${ }^{(3)}$.

Nos dias atuais, o desenvolvimento científico determinou a necessidade de uma formação profissional que possibilite ao enfermeiro uma maior especialização em sua prática, com o domínio de avançadas técnicas de saúde. Contemporaneamente, o movimento da Reforma Sanitária Brasileira inspirou um redimensionamento no processo de formação de enfermeiros sob uma perspectiva baseada no perfil sanitário e epidemiológico da população e na prática profissional reflexiva ${ }^{(3)}$.
Assim, a preocupação com a educação em Enfermagem se faz presente, havendo uma busca constante de estratégias, principalmente através da reformulação curricular, no sentido de possibilitar uma formação comprometida com a realidade social, crítica e transformadora, independentemente do contexto no qual essa prática se efetive ${ }^{(4)}$.

A educação como um todo, na atualidade, passa por um processo de transição paradigmática que implica na necessidade de redefinição do papel das instituições formadoras, bem como dos docentes e discentes no cenário educacional. Busca-se, portanto, a superação das contradições originadas nas tendências teóricas que fundamentam o processo educacional dominante, pela inserção de novas estratégias de ensino que concorram para a formação de um perfil profissional capaz de responder às necessidades sociais da saúde ${ }^{(5)}$.

Dado que os estágios supervisionados constituem uma oportunidade de exercitar a síntese dos conhecimentos adquiridos ao longo do curso de graduação e é obrigatório pela matriz curricular vigente, justifica-se a sua utilização como espaço para pesquisa, pela possibilidade de identificação das tendências pedagógicas direcionadoras desse processo, bem como para reflexões acerca do processo avaliativo e das contradições da prática educativa no que concerne às concepções teóricas que a fundamentam.

No Estágio Curricular Supervisionado do curso de graduação em Enfermagem do Centro de Ciências da Saúde da Universidade Federal da Paraíba - ECS/CCS/UFPB, observamos a ausência da proposição de uma abordagem pedagógica, que subsidie o processo avaliativo, nas normas que orientam a condução didático-pedagógica desse importante componente do processo formativo.

Partimos do pressuposto de que o processo avaliativo nos estágios supervisionados encontra-se vinculado a uma abordagem pedagógica tradicional sendo, portanto, realizado de forma circunstancial. Em que pese a determinação legal que garante aos docentes a liberdade de escolha da concepção pedagógica que subsidiará sua prática educativa, a explicitação dessa abordagem e de seu processo avaliativo poderá favorecer a utilização de todos os recursos que a vertente pedagógica possa oferecer, ajudando o aluno a suprir eventuais deficiências, bem como ajudá-lo no processo de matização dos conhecimentos adquiridos. Dessa forma, o objeto de estudo dessa investigação é o processo avaliativo realizado no Estágio Supervisionado do curso de graduação em 
Enfermagem, no qual se busca investigar o processo avaliativo, detectar a abordagem pedagógica à qual está vinculado e propor alternativa para superação das contradições visualizadas.

Com base no exposto, questiona-se: a indicação da abordagem pedagógica para subsidiar o processo avaliativo nos estágios supervisionados favorecerá o processo ensino-aprendizagem dos alunos durante a vigência do Estágio?

Em busca de resposta para essa questão, formulamos os seguintes objetivos: Compreender o processo avaliativo em vigência no Estágio Supervisionado curricular do CCS/UFPB como elemento constitutivo do processo de formação de enfermeiros; Identificar a abordagem pedagógica que subsidia o processo avaliativo no Estágio Supervisionado curricular do curso de graduação em enfermagem do CCS/UFPB e, verificar as contradições ocorridas no processo de avaliação dos alunos durante o Estágio Supervisionado curricular do CCS/UFPB.

\section{ANTECEDENTES HISTÓRICOS DOS PROCESSOS EDUCATIVOS E SUA DETERMINAÇÃO SOBRE AS FORMAS DE AVALIAÇÃO NA ATUALIDADE}

A atual Lei de Diretrizes e Bases da Educação Nacional $^{(6)}$, sancionada pelo Presidente da República em 20 de dezembro de 1996, determinou em seu artigo $9^{\circ}$ e parágrafo $1^{\circ}$ do artigo $87^{\circ}$, respectivamente, que caberia à União, em colaboração com os Estados, Distrito Federal e Municípios, a elaboração do Plano Nacional de Educação (PNE) ${ }^{(7)}$. A lei determinou também que esse plano deveria ser encaminhando ao Congresso Nacional no prazo de um ano, a partir da publicação da referida lei, contendo as diretrizes e metas válidas para os dez anos seguintes.

Tendo em vista o cenário político, social e econômico do final do século XX no Brasil, que no campo da educação já refletia uma submissão do ensino aos interesses do mercado, as entidades que compunham o Fórum Nacional em Defesa da Escola Pública, sob a perspectiva de uma educação como direito de todos e dever do estado, propuseram um Plano Nacional de Educação que refletisse uma demanda social por educação para a cidadania ${ }^{(5)}$.

O Plano Nacional de Educação - Proposta da Sociedade Brasileira foi consolidado em novembro de 1997 no II Congresso Nacional de Educação - CONED, realizado na cidade de Belo Horizonte, obrigando o governo federal a elaborar uma proposta (Plano Nacional de Educação proposta do Ministério da Educação e Cultura - PNE/MEC) que evidenciava intenções de operacionalizar políticas educacionais excludentes ${ }^{(5)}$.

Tendo sido apresentado ao Congresso Nacional em dezembro de 1997, o Plano Nacional de Educação - Proposta da Sociedade Brasileira foi transformado em Projeto de Lei (PL No 4.155/98) em fevereiro de 1998 e anexado ao PNE/MEC (PL N ${ }^{\circ}$ 4.173/98) nesse mesmo ano. O documento final constava de trechos do Plano Nacional de Educação - Proposta da Sociedade Brasileira nas partes introdutórias, tendo sido mantidas as metas do PNE/ MEC no corpo do Plano ${ }^{(5)}$.

Através do substitutivo do relator, deputado Nelson Marchezan (PSDB/RS), o PNE/MEC tornouse o Projeto de Lei a ser aprovado na Comissão de Educação da Câmara, recebendo a sanção presidencial em 9 de janeiro de 2001, sob a égide da Lei 10.172, após três anos de tramitação pelo Congresso Nacional. O PNE trouxe, em seu conjunto, o diagnóstico e as diretrizes, bem como objetivos e metas para os diferentes níveis de educação, inclusive o ensino superior ${ }^{(5,7)}$.

$\mathrm{O}$ artigo $2^{\circ}$ da referida Lei assevera que Estados, Distrito Federal e Municípios se responsabilizarão pela elaboração de seus planos decenais de educação, tendo como base o Plano Nacional de Educação. No caso particular da educação superior, o PNE traz em seus objetivos e metas o estabelecimento de Diretrizes Curriculares que garantem a flexibilidade e diversidade nos programas de estudos oferecidos pelas diferentes instituições de educação superior, a fim de que possam atender às necessidades de seus alunos, bem como às peculiaridades das regiões ${ }^{(7)}$.

As Diretrizes Curriculares, ao serem legalmente estabelecidas através da Resolução CNE/ CES N.03/2001 ${ }^{(8)}$, levaram as instituições de ensino superior a conquistar o direito de definir as estruturas curriculares de seus cursos, a partir da elaboração de um Projeto Político-Pedagógico, no qual estarão definidas as competências e habilidades que se deseja desenvolver com os alunos, sendo, desse modo, capazes de atender às demandas sociais.

Um projeto pedagógico consiste em uma proposta integrada de trabalho, na qual devem estar descritos conjuntos de habilidades cognitivas, afetivas e psicomotoras que se pretende desenvolver em uma determinada clientela, bem como referenciais a ela associados e a metodologia a ser adotada, incluindo 
formas de ensino e avaliação ${ }^{(9)}$. Os projetos pedagógicos são necessariamente políticos, já que pressupõem a articulação de compromissos sóciopolíticos com interesses reais e coletivos ${ }^{(10)}$.

De acordo com a atual Lei de Diretrizes e Bases da Educação Nacional, em seu artigo $3^{\circ}$, inciso III, o ensino deverá ser ministrado com base no pluralismo de idéias e concepções pedagógicas, também chamadas de vertentes ou abordagens, que fundamentam a prática educativa dos docentes ao longo do processo educativo. Dado que o processo educativo é intencional e se efetiva por meio de uma prática educativa, a compreensão de como essa prática se operacionaliza fornece indícios da concepção, vertente ou abordagem pedagógica que ampara todo o processo.

Para Gadotti ${ }^{(11)}$, o desenvolvimento de novas tecnologias, especialmente as tecnologias da informação, transformou profundamente a forma como a sociedade se organiza, criando novos espaços de conhecimento e exigindo uma educação voltada para a formação de indivíduos intelectualmente autônomos, críticos, criativos e comprometidos com a realidade social.

Neste sentido, um processo pedagógico que se propõe a desenvolver nos indivíduos uma consciência crítica deve dar atenção especial ao processo avaliativo, buscando não desenvolvê-lo segundo uma lógica de classificação, de medição e de disciplinamento, o que acabará por determinar relações de poder entre aqueles envolvidos em sua construção. Trata-se de ressignificar a prática pedagógica com especial atenção à práxis avaliativa, se quisermos fazer acontecer nos cenários em que atuamos a formação crítica que teoricamente defendemos ${ }^{(12)}$.

\section{PROCESSOS AVALIATIVOS NAS ABORDAGENS PEDAGÓGICAS SEGUNDO A CLASSIFICAÇÃO DE MARIA DA GRAÇA NICOLLETI MIZUKAMI}

Segundo Mizukami ${ }^{(13)}$, a abordagem Tradicional compreende uma prática educativa estabelecida através dos anos. Nela o ensino está centrado na figura do professor, detentor do saber, cabendo ao aluno incorporar passivamente os conhecimentos que são externos a ele. O processo avaliativo decorrente da concepção tradicional visa a reprodução dos conteúdos transmitidos com exatidão e em quantidade, através de provas, exames, chamadas orais, exercícios. A educação tem caráter de instrução, cabendo à escola a transmissão formal do conhecimento.

$\mathrm{Na}$ abordagem Comportamentalista, segundo orientação empirista, o conhecimento é concebido como resultado direto da experiência ou experimentação planejada e o educando é considerado mero recipiente de informações e reflexões. O processo avaliativo tem um ritmo próprio de desenvolvimento e consiste em constatar se o aluno aprendeu, segundo os objetivos pré-estabelecidos, podendo estar presente no início (pré-testagem), durante (definição de objetivos terminais) e no final do processo de aprendizagem, a fim de verificar se os objetivos foram alcançados.

Para a abordagem Humanista, o enfoque no processo ensino-aprendizagem está no sujeito. C. Rogers e A. Neill são seus principais representantes. A abordagem rogeriana concebe o "ensino centrado no aluno", com ênfase nas relações interpessoais e no crescimento delas resultantes.

$\mathrm{O}$ uso de técnicas avaliativas que visam à reprodução de produtos de aprendizagem e competências do professor é alvo de críticas tanto por parte de Rogers quanto por Neill. Para estes, somente o indivíduo é capaz de conhecer verdadeiramente a sua experiência, o que implica dizer que esta experiência só poderá ser julgada a partir de critérios internos desse organismo. Caberá, então, ao aluno definir e aplicar seus critérios de avaliação, segundo objetivos próprios.

A abordagem Cognitivista concebe a aprendizagem como mais do que o produto do ambiente, das pessoas ou de fatores externos aos alunos. A ênfase está nos processos cognitivos, considerando-se as formas pelas quais as pessoas lidam com os estímulos ambientais, organizam dados, sentem e resolvem problemas, adquirem conceitos e empregam símbolos verbais. Tem o suíço Jean Piaget como seu principal representante. A avaliação terá de ser realizada a partir de parâmetros extraídos da própria teoria e implicará em verificar se o aluno já adquiriu noções, realizou operações e relações. As reproduções livres, as explicações práticas e a aplicação dos conhecimentos em situações variadas constituem formas de avaliação nessa abordagem. As soluções apresentadas pelos alunos são sempre consideradas, sejam elas erradas, incompletas ou distorcidas, pois se concebe que a interpretação que o mesmo tem do mundo, dos fatos, da causalidade, é realizada de forma qualitativamente diferente de acordo com o estágio do desenvolvimento em que se encontra.

A abordagem Sócio-Cultural parte sempre do 
que é inerente ao povo, buscando resgatar valores próprios dessas camadas da população, para que estas possam se assumir como sujeitos históricos. A obra referente a essa abordagem, mais significativa e difundida no contexto brasileiro, é a de Paulo Freire, caracterizada pela preocupação com a cultura popular. Quanto ao processo avaliativo, consiste na autoavaliação e/ou avaliação mútua e permanente sobre a prática educativa, por parte de professores e alunos, ou seja, considerando tal prática em todos os seus aspectos, sem se restringir à avaliação de conteúdos. Desse modo, qualquer processo formal de exames deixa de ter sentido.

\section{ASPECTOS LEGAIS DO PROCESSO AVALIATIVO NO ESTÁGIO CURRICULAR DO CURSO DE GRADUAÇÃO EM ENFERMAGEM DO CCS/UFPB}

A Resolução ${ }^{\circ}$ 02/2004 que aprova o regulamento do Estágio Supervisionado Curricular (ESC) do curso de graduação em Enfermagem da Universidade Federal da Paraíba conceitua essa fase do processo formativo como período destinado à formação do aluno através da aplicação dos conhecimentos teórico-práticos adquiridos nas diversas disciplinas que integram o currículo à prática profissional, de forma que possam contribuir para desenvolvimento de sua qualificação profissional fornecendo-lhe vivência no cuidar do indivíduo, família e comunidade, no contexto de sua realidade social ${ }^{(14)}$.

O ESC constitui componente curricular obrigatório e é desenvolvido sob a supervisão docente, em hospitais, ambulatórios e rede básica de serviços de saúde, com programação e avaliação específicas. São objetivos do ESC proporcionar experiência acadêmica e profissional através da realização das atividades inerentes à Enfermagem; desenvolver no aluno a capacidade de buscar a integração entre a teoria e a prática profissional e fortalecer o processo de integração ensino e serviço ${ }^{(14)}$.

Quanto ao campo de Estágio, as atividades do ESC são realizadas em Unidades Básicas de Saúde, ambulatórios e unidades hospitalares, incluindo as clínicas: médica; cirúrgica; pediátrica; obstétrica e de doenças infecto-contagiosas; centro cirúrgico e centro de terapia intensiva, de instituições públicas e ou privadas, mediante a celebração de convênios entre a Universidade Federal da Paraíba e as instituições nas quais estão inseridas as respectivas unidades.
A Resolução $n^{\circ} 02 / 2004^{(14)}$ conceitua supervisão de estágio como uma atividade destinada a acompanhar o aluno, de forma a garantir a consecução dos objetivos estabelecidos. Informa que a supervisão será exercida por docentes do curso de Enfermagem e enfermeiros assistenciais das unidades conveniadas, nas quais serão desenvolvidas as atividades dos estágios. $\mathrm{O}$ artigo $10^{\circ}$ da referida Resolução assegura que a supervisão do estágio deverá ser exercida de acordo com as seguintes modalidades: a) Supervisão direta, que consiste no processo contínuo de acompanhamento, orientação e avaliação das atividades (grifo nosso) desenvolvidas durante os estágios, realizadas pelo enfermeiro do serviço. b) Supervisão indireta, que consiste no processo sistemático de acompanhamento, orientação e avaliação das atividades (grifo nosso) através de visitas sistemáticas realizadas pelo docente.

Especificamente sobre o processo avaliativo, a Resolução em lide assevera que a avaliação do ESC, como parte integrante do processo de ensinoaprendizagem, incidirá sobre a freqüência e o aproveitamento do estagiário e deverá ser efetivada sob dois enfoques: avaliação do estágio e avaliação do estagiário. Informa, ainda, que a avaliação de cada estágio será realizada através de reuniões sistemáticas pelos docentes, enfermeiros e discentes envolvidos, com a finalidade de prover o curso de graduação em Enfermagem de informações que subsidiem o processo de aprimoramento das atividades do Estágio Supervisionado.

O documento assevera, ainda, que a avaliação do estagiário será realizada pelo docente e enfermeiro supervisor direto, de forma sistemática e contínua e compreenderá aspectos qualitativos e quantitativos com base na análise dos seguintes elementos: a) Domínio do conhecimento científico; b) Habilidade técnica; c) Postura profissional; d) Elaboração de relatórios. A avaliação dos elementos enumerados anteriormente será definida em folha individual de avaliação, a qual deverá ser subscrita pelo enfermeiro (supervisor direto), pelo docente (supervisor indireto) e pelo aluno. Será considerado aprovado o aluno que, somativamente, obtiver a média geral 7,0 (sete) e freqüência integral em cada estágio.

\section{METODOLOGIA}

Tratou-se de uma pesquisa exploratória e descritiva, com abordagem qualitativa do processo 
avaliativo em vigência no Estágio Supervisionado do curso de graduação em Enfermagem do CCS/UFPB, desenvolvida no ano de 2007.

Para obtenção do material empírico foram utilizados dois instrumentos, sendo um dirigido aos docentes responsáveis pelo processo avaliativo no Estágio e outro aos enfermeiros de serviço, co-responsáveis pelo processo. O instrumento I, dirigido aos docentes, foi elaborado com vistas à obtenção de informações sobre a realização do processo avaliativo durante o Estágio Supervisionado sob a ótica da docência, enquanto o instrumento II, dirigido aos enfermeiros de serviço, objetivou fazer emergir o posicionamento dos enfermeiros assistenciais sobre esse processo.

Para proceder à obtenção do material empírico foi utilizada a técnica da entrevista semi-estruturada. A análise dos dados coletados foi realizada mediante a técnica de Análise de Discurso na vertente proposta por Fiorin ${ }^{(15)}$. A rigor, a pesquisa foi iniciada após liberação pelo Comitê de Ética em Pesquisa do Hospital Universitário Lauro Wanderley. O primeiro contato com os supervisores indiretos se deu por ocasião da reunião do Estágio Supervisionado, na qual estiveram presentes os supervisores diretos, representando cada umas das seis clínicas nas quais haveria o rodízio dos alunos. Os rodízios compreendem um período de 10 a 12 dias em cada clínica.

Os entrevistados manifestaram interesse e disponibilidade de tempo para participar da pesquisa. Os encontros com os supervisores foram realizados no próprio ambiente de trabalho desses profissionais. A sistemática adotada foi aguardar a conclusão das atividades de supervisão aos alunos; explicar os objetivos e propósitos da entrevista; solicitar a leitura atenciosa do Termo de Consentimento Livre e Esclarecido; expor a cópia de liberação da pesquisa pelo Comitê de Ética em Pesquisa do Hospital Universitário Lauro Wanderley e, finalmente, solicitar permissão para gravação da entrevista.

Foram entrevistados dois (02) supervisores diretos e dois (02) supervisores indiretos. As entrevistas ocorreram durante o mês de fevereiro de 2007. Os textos obtidos a partir das entrevistas foram analisados separadamente, atribuindo a cada sujeito uma legenda segundo sua função como supervisor e ordem de coleta. Depois os textos foram confrontados e identificados para a identificação das figuras e dos temas relacionados ao objeto e aos objetivos do estudo.

Os pontos de identificação e convergência dos trechos das entrevistas foram relacionados aos elementos característicos de cada abordagem pedagógica, segundo a classificação de Mizukami ${ }^{(13)}$, com vistas à identificação da vertente que amparava a ação docente.

\section{ANÁLISE E DISCUSSÃO DOS RESULTADOS}

O sistema avaliativo dos processos educativos empregados ao longo da história no mundo ocidental permanece praticamente inalterado, embora tenha sido alvo constante de críticas por diversos estudiosos do assunto. Entretanto, apesar da diversidade de estudos sobre avaliação, existe certa continuidade linear na forma como o tema é abordado, mantendo-se sempre a mesma concepção de ser humano e sociedade, de educação e de aprendizagem ${ }^{(16)}$.

Hoffmann ${ }^{(16)}$ nos convida a repensar a prática avaliativa tendo em vista as contradições que se estabelecem em torno dessa prática, enquanto para Luckesi $^{(17)}$ a prática avaliativa vem sendo efetuada a serviço de uma pedagogia fundamentada em um modelo teórico conservador de sociedade, e a superação dessa condição só se dará a partir do estabelecimento de uma avaliação cujo principal objetivo é o diagnóstico do processo de aprendizagem e não a classificação do educando.

A análise da avaliação realizada por supervisores diretos (enfermeiros de serviço) e supervisores indiretos (docentes), à luz das abordagens pedagógicas propostas por Mizukami ${ }^{(13)}$, evidenciou a utilização de vários elementos característicos de cada abordagem, alicerçando suas práticas avaliativas.

Com base nessa evidência, e considerando as atitudes dos supervisores ou ênfase em suas ações pedagógicas no Estágio Supervisionado do curso de graduação em Enfermagem da UFPB, classificou-se a prática avaliativa de cada um como decorrente das abordagens pedagógicas que lhes forneceram os elementos característicos.

No cenário de pesquisa, observou-se que a ênfase do supervisor indireto recai sobre itens que desconsideram o desenvolvimento intelectual do aluno, reduzindo sua observação a questões pouco relacionadas com o pretendido desenvolvimento crítico, reflexivo e questionador, necessário à formação de profissionais mais engajados política e socialmente, conforme pode ser verificado no depoimento a seguir:

[...] a gente participa de forma indireta, quando ele chama e diz "o aluno tal, ele não chega cedo, ele fica muito sentado no balcão, falta iniciativa, é 
pouco interessado, não tem uma postura, não usa a vestimenta, que deve ser branca".

Ao descrever os aspectos e condutas do aluno que exigem a atenção dos supervisores, o docente evidencia critérios de avaliação fundamentalmente técnicos. Segundo Delors ${ }^{(18)}$, a educação deverá considerar a necessidade de uma aprendizagem ao longo da vida, a fim de responder às demandas da sociedade do conhecimento, fundamentando-se, para tanto, em quatro pilares do conhecimento: aprender a conhecer, ou adquirir meios de compreensão; aprender a fazer, de forma a agir sobre o meio; aprender a viver juntos, a fim de poder participar e cooperar com os outros; e aprender a ser, via fundamental, que integra as demais. $\mathrm{O}$ autor prossegue afirmando que, em regra geral, o ensino formal direciona-se quase que exclusivamente para o aprender a conhecer e, em menor escala, para o aprender a fazer, quando deveria ser dada igual atenção aos quatro pilares.

No ensino tradicional, destaca-se o aprender a fazer, em um sentido que para a área da saúde como um todo e, consequientemente para a Enfermagem, implica em executar adequadamente procedimentos e técnicas, visando reproduzir com exatidão o conteúdo teórico transmitido. A repetição das atividades garantirá a retenção do conteúdo ensinado, sendo indispensável para que o aluno seja capaz de responder a situações novas segundo um padrão estabelecido em situações anteriores. Segundo Mizukami ${ }^{(13)}$, o desempenho do aluno é medido pela quantidade e exatidão das informações que ele consegue reproduzir. No depoimento a seguir, o entrevistado corrobora com a assertiva do autor:

Na avaliação, eu considero a desenvoltura do aluno, o desenvolvimento da prática conforme o que aprendeu na teoria e a assiduidade. O desempenho, principalmente, a desenvoltura.

Para Delors ${ }^{(18)}$ o aprender a fazer não pode continuar a ter um significado que se restrinja a preparar alguém para realizar procedimentos técnicos, mas, antes, deverá encerrar a dimensão cognitiva, a reflexão, o questionamento, mesmo sobre tarefas puramente materiais. A ênfase em critérios dessa natureza evidencia um processo avaliativo característico, conforme pode ser verificado no depoimento a seguir:

Essa avaliação é feita junto com o supervisor direto que, nesse caso, é o enfermeiro. Tem uns pontos para avaliação que ele deve observar: assiduidade, pontualidade, o envolvimento com a equipe de Enfermagem, com a equipe de saúde e também com o paciente e com os colegas. Esses pontos, é só ir seguindo. É passado para ele, porque ele tem naquela pasta o impresso com esses itens, que é só observar. E muitos já fazem isso há muito tempo, então eles já sabem de cor como é feita a avaliação.

A utilização de parâmetros previamente definidos está de acordo com a Resolução no 02/2004 da UFPB ${ }^{(14)}$, segundo a qual a avaliação do estagiário compreenderá aspectos qualitativos e quantitativos com base na análise dos seguintes elementos: domínio do conhecimento científico, habilidade técnica, postura profissional e a elaboração de relatórios.

O processo avaliativo utilizado no cenário da pesquisa é institucionalmente desenhado para a perseguição de uma seqüência de parâmetros que padronizam ações e prescrevem resultados. Ignorase, desse modo, não somente as diferenças individuais dos avaliadores, como também as diferenças individuais dos alunos, avaliados todos segundo os mesmos critérios. Há uma forte tendência a se tratar a todos de forma igual, uniformizando o ritual de trabalho, buscando adquirir os mesmos conhecimentos, de modo a atingir os mesmos objetivos de aprendizagem.

No depoimento a seguir, a supervisora direta afirma fazer uso dos critérios definidos como suporte para realizar a sua avaliação:

Geralmente eu costumo seguir o que o professor deixa anexado naquela fichinha. Eu dou um lida e, em cima daqueles critérios, eu procuro avaliar da melhor forma possivel. Geralmente, através da observação.

Embora afirme fazer uso de um padrão avaliativo definido pela regulamentação do estágio em estudo, a supervisora direta relata que "procura avaliar da melhor forma possível", fazendo uso da observação dos alunos em suas atividades. Ao discorrer sobre os parâmetros de avaliação, outra supervisora direta assume a utilização de um tipo próprio de avaliação dos estagiários:

Eu estabeleço os critérios, porque avalio o que eu acho mais importante.

Tal postura, embora contrarie o regulamento do estágio, é reconhecida por uma das supervisoras 
indiretas como uma prática comum no processo avaliativo em estudo:

[...] a gente tem dificuldade, como existem em todo canto, porque nem todo mundo avalia do mesmo jeito, apesar dos critérios. Porque isso vai muito da característica de cada um.

A docente em questão reconhece que as características do avaliador se sobressaem e o tipo de avaliação varia conforme o sujeito que avalia o que compreende ser uma dificuldade em tal processo. De acordo com Mizukami ${ }^{(13)}$, em uma prática educativa na qual o professor é responsável por desenvolver seu próprio repertório, o processo de ensino dependerá do interrelacionamento, do caráter individual do professor com o caráter individual do aluno, enfatizando, desse modo, a relação pedagógica bem como o estabelecimento de um clima favorável ao desenvolvimento das pessoas, que possibilite liberdade para aprender.

Uma educação centrada no aluno visa proporcionar experiências significativas que lhe permitam desenvolver características inerentes à sua natureza. Desse modo, os processos de ensino deverão proporcionar aos alunos os meios para buscarem o conhecimento por si mesmos ${ }^{(19)}$.

No depoimento a seguir, observa-se que a auto-avaliação é o recurso avaliativo empregado pela supervisora direta nas situações em que não se sente segura para avaliar o aluno:

\section{[...] tem aluno que eu não sinto dificuldade nenhuma} de avaliar, até gosto. Chego lá, coloco aquela nota lá com prazer, mas tem uns que eu fico insegura prá dar uma nota e faço uma auto-avaliação. Quando eu me sinto insegura eu boto prá ele. Aí, em cima do que ele me diz, é que eu faço a avaliação.

Sob tal perspectiva, o aluno assume o papel principal em sua avaliação, definindo critérios e objetivos atingidos, o que concorre para sua autorealização. Outra particularidade observada no processo avaliativo em estudo diz respeito à ênfase nos processos cognitivos do avaliado, em sua postura de busca ativa pelo conhecimento:

Procuro ver sempre aquele aluno que é mais interessado, aquele mais dedicado, aqueles que gostam de perguntar. Eu gosto daqueles que chegam fazendo pergunta, procurando tirar as dúvidas.
Neste depoimento, a supervisora direta afirma sua preferência em avaliar alunos que apresentam uma postura investigativa, que recorrem à ela para realizar questionamentos e sanar dúvidas, priorizando, desse modo, as atividades do sujeito em direção a um processo de descoberta.

O conhecimento é produto da interação entre homem e mundo, só podendo ser atingido quando assegurada a autonomia intelectual do sujeito. Desse modo, destaca-se a importância de oferecer ao aluno liberdade de ação motora, verbal e mental, para que ele seja capaz de, posteriormente, intervir no processo sócio-cultural e de realizar transformações sociais ${ }^{(13)}$.

Ao descrever a avaliação do estágio, as supervisoras relatam uma prática que se propõe a constatar se os objetivos propostos foram atingidos em diferentes momentos durante as atividades:

As reuniões são a cada rodízio e funcionavam como relatório. A gente tem um acompanhamento mais de perto, então os problemas vão acontecendo e a gente vai solucionando esses problemas logo, dentro do processo e eu acho que ficou muito melhor.

A sequiência relatada retrata um processo avaliativo que consiste em constatar se o aluno aprendeu, segundo objetivos pré-estabelecidos, sob tal perspectiva, a qualidade do ensino dependerá da organização eficiente de condições estimuladoras que permitam que o aluno saia da situação de aprendizagem diferente de quando entrou.

No que se refere às funções dos supervisores direto e indireto no processo avaliativo, os depoimentos revelam que a avaliação fica a cargo dos primeiros, cabendo aos supervisores indiretos o planejamento e acompanhamento das atividades do estágio, bem como a resolução de eventuais problemas:

A avaliação é feita pelo supervisor direto porque é quem está realmente com o interno, durante as 6 horas. Porque o supervisor indireto está em esquema de rodízio e não pode estar o tempo inteiro com o interno em todas as clínicas.

$O$ supervisor indireto, ele apenas acompanha o aluno, porque, na verdade, ele não está lá todo dia, cedinho, para ver as atividades. Então, fica fazendo esclarecimentos de algumas dúvidas, de trocas, de adequação do aluno. Às vezes, ocorrem problemas de relacionamento, dificuldade do aluno com a equipe 
de enfermagem, e o supervisor faz esse intercâmbio.

Ao discorrer sobre o Estágio Supervisionado, Buriolla ${ }^{(20)}$ argumenta que o papel da supervisão nesse contexto é complexo e polêmico e que o supervisor, na maioria das vezes, se restringe a sanar eventuais dúvidas, quando deveria buscar refletir com o aluno a prática experienciada.

O depoimento de uma das supervisoras diretas fornece novos elementos acerca de sua função no processo avaliativo, no cenário investigado:

Apesar de estar muito atarefada naquele balcão, eu procuro observar um a um, da melhor forma possivel, mesmo deixando a desejar, porque não dá tempo de ficar, lado a lado ali, acompanhando tudo. $\mathrm{Na}$ verdade, não dá.

Tal depoimento revela o esforço da supervisora direta no sentido de observar as atividades dos alunos e a impossibilidade de acompanhá-los. Durante o Estágio Curricular, o aluno passa grande parte do tempo acompanhando, observando e auxiliando as atividades diárias do enfermeiro e, para que a aprendizagem ocorra de forma adequada, faz-se necessário que esse enfermeiro esteja preparado para conduzir o aluno a uma aprendizagem significativa, de acordo com os objetivos propostos. O autor reconhece que a falta de tempo do enfermeiro para orientar e acompanhar os alunos é comum em campo de estágio, o que pode ser atribuído à falta de funcionários no setor e ao excesso de pacientes sob os cuidados da Enfermagem ${ }^{(21)}$.

Ainda sobre as funções dos supervisores, observou-se que, embora caiba ao supervisor direto a avaliação dos alunos, no depoimento a seguir a supervisora indireta afirma crer que tal avaliação deveria ser feita de outra forma:

[...] a gente não interfere na nota que ele vai dar, porque não é feito assim. Na verdade, era prá ser tudo junto, mas nunca dá prá fazer aluno, enfermeiro e o supervisor indireto, para fazer essa avaliação, que era o ideal.

Em seu depoimento, a supervisora indireta descreve o real e o ideal no processo avaliativo investigado, afirmando que tal processo deveria contar com a participação de todos os envolvidos no estágio, alunos, enfermeiro e docentes, embora reconheça que não haja possibilidades para tanto.
O processo ensino-aprendizagem no Estágio Supervisionado não ocorre de forma isolada e, em função disso, requer o envolvimento de três personagens: o aluno, o docente e o enfermeiro assistencial, os quais assumem papel específico nesse contexto ${ }^{(21)}$.

\section{CONSIDERAÇÕES FINAIS}

A opção dos professores por modelos assentados na transmissão de conhecimentos, sob uma perspectiva de avaliação que visa a reprodução dos conteúdos comunicados em sala de aula, tendo como base didático-pedagógica a abordagem Tradicional, observada neste estudo sobre o processo avaliativo no Estágio Supervisionado do curso de graduação em Enfermagem da UFPB, aponta para a necessidade de ressignificar essa prática no sentido de promover um processo avaliativo fundamentado na concepção de educação articulada com as realidades sociais.

$\mathrm{O}$ processo avaliativo verificado se restringe à atribuição de notas de acordo com o desempenho técnico do aluno, deixando de considerar outras dimensões do processo ensino-aprendizagem. Essa restrição evidencia o uso de abordagens que parcializam a ação pedagógica, negando seu caráter de totalidade, sendo urgente a necessidade de buscar uma perspectiva integradora da ação pedagógica.

Há uma evidente desconsideração do caráter pedagógico do campo de estágio, em que as atividades não são direcionadas no sentido de promover uma aprendizagem significativa, mas, antes, os estagiários devem realizar atividades que os supervisores diretos consideram importantes ou necessárias, o que, na maioria das vezes, se restringe à realização de procedimentos estritamente técnicos, como forma de diminuir o trabalho da equipe. Desse modo, o estagiário muitas vezes assume o papel de mão-de-obra disponível, sendo exigido dele que tenha pleno domínio do conhecimento teórico e técnico, mesmo que não tenha tido oportunidade de realizar alguns procedimentos anteriormente.

Observou-se, ainda, a utilização das abordagens Humanista, Cognitiva e Comportamental no processo avaliativo em estudo, o que, embora evidencie um esforço dos supervisores no sentido de buscar um novo direcionamento de referenciais pedagógicos, constituem práticas isoladas que não possibilitam a transposição das limitações e dificuldade desse processo.

As contradições no processo avaliativo puderam ser verificadas com relação à função dos 
supervisores indiretos, que se restringia ao acompanhamento do aluno de forma geral, dispondo de pouco tempo para tanto, agindo efetivamente apenas para a resolução de eventuais problemas.

Em relação aos supervisores diretos, a contradição se faz presente quando fica evidente que, embora se exija deles uma supervisão contínua por serem os únicos capazes de acompanhar os alunos continuamente, muitas vezes se vêem impossibilitados de realizar esse acompanhamento em função da quantidade de tarefas sob suas responsabilidades, o que significa dizer que o aluno permanece muito tempo sem uma supervisão contínua durante o estágio.

A necessidade de mudanças no processo avaliativo, no cenário investigado, é evidente e urgente, podendo dar-se em curto prazo desde que seja reconhecida, assumida e conduzida como tarefa comum entre docentes, alunos e enfermeiros assistenciais, a partir do compartilhamento de tarefas e compromissos no sentido de possibilitar um processo avaliativo condizente com a exigência de formação de profissionais técnica e politicamente competentes. No caso específico de docentes e enfermeiros assistenciais, a busca por transformações deverá ser fundamentada na avaliação de suas bases teóricometodológicas e na percepção de como sua prática afeta a vivência do aluno, no sentido de contribuir ou de se constituir em um entrave à aprendizagem e ao necessário desenvolvimento crítico e reflexivo.

A avaliação é um importante elemento constitutivo da ação pedagógica, e deverá ser reconhecida como tal a fim de que possa se configurar em um espaço de aprendizagem, perdendo, desse modo, o caráter classificatório e excludente comumente verificado. O processo avaliativo poderá ser visto ainda como um importante instrumento que subsidia a melhoria das condições de ensino e aprendizagem, ao disponibilizar informações que permitam que a prática pedagógica seja repensada e resignificada.

A indicação da abordagem pedagógica que subsidia o processo avaliativo nos Estágios Supervisionados constitui um importante passo nesse sentido, como forma de favorecer o processo ensinoaprendizagem dos alunos, a fim de melhor atender às exigências da sociedade para com a Universidade, cuja missão é formar cidadãos conscientes, analíticos e críticos, comprometidos com as necessidades sociais.

\section{REFERÊNCIAS}

1 Germano RM. Educação e ideologia da enfermagem no
Brasil. São Paulo: Cortez; 1985.

2 Araújo LCA. Tendências pedagógicas no ensino médio de enfermagem: representações sociais [dissertação]. João Pessoa (PB): Universidade Federal da Paraíba; 2001.

3 Pinto M.B. Ensino de enfermagem em saúde mental para formação de técnicos na perspectiva da reforma psiquiátrica [dissertação]. João Pessoa (PB): Universidade Federal da Paraíba; 2005.

4 Ponce de Leon CGRM. Formação de formadores: a Prática Educativa em um Programa de Pós-Graduação em Enfermagem [dissertação]. João Pessoa (PB): Universidade Federal da Paraíba; 2005.

5 Silva CC. Competências na prática educativa para constituição da força de trabalho em saúde: um desafio aos educadores [tese]. São Paulo (SP): Escola de Enfermagem da Universidade de São Paulo; 2003.

6 Brasil. Lei n. 9394, de 20 de dezembro de 1996. Estabelece as Diretrizes e Bases da Educação Nacional. Brasília (DF): Senado; 1996.

7 Brasil. Lei n. 10.172, de 09 de janeiro de 2001. Aprova o Plano Nacional de Educação e da outras providências. Diário Oficial da Republica Federativa do Brasil, Brasília, 10 Jan. 2001.

8 Conselho Nacional de Educação. Câmara de Educação Superior. Resolução CNE/CES n. 03, de 7 de novembro de 2001. Institui Diretrizes Curriculares Nacionais do Curso de Graduação em Enfermagem. Diário Oficial da União, Brasília, 9 de Novembro de 2001.

9 Souza CBG. O projeto pedagógico com instrumento de participação e qualidade no ensino superior. Araraquara: ACL/UNESP; 1995. /Mimeografado/.

10 Saupe R; ALVES E. Contribuição à construção de projetos político-pedagógicos na enfermagem. Rev Latino-am Enferm. 2000 Abr;8(2). Acesso em: 19 Nov. 2006. Disponível em: 〈http://www.scielo.br/scielo.php>.

11 Gadotti M. Perspectivas atuais da educação. In: Ferreira VS, organizador. Educação: novos caminhos em um novo milênio. $2^{\mathrm{a}}$ ed. João Pessoa: Autores Associados; 2001.p. 11-20.

12 Sordi MRL, Bagnato MHS Subsídios para uma formação profissional crítico-reflexiva na área da saúde: o desafio da virada do século. Rev Latino-am Enferm. 1998Abr;6(2). Acesso em: 19 Nov 2006. Disponível em: <http://www.scielo.br/scielo.php>. 
13 Mizukami MGN. Ensino: as abordagens do processo. São Paulo: Pedagógica Universitária; 1986.

14 Universidade Federal da Paraíba. Resolução n. 02, de 30 de março de 2004. Aprova o Regulamento do Estágio Supervisionado Curricular do Curso de Graduação em Enfermagem da Universidade Federal da Paraíba. João Pessoa, 2004

15 Fiorin JL. Elementos de análise do discurso. São Paulo: Contexto/Edusp; 1990.

16 Hoffmann JML. Pontos e Contrapontos: do pensar ao agir em avaliação. Porto Alegre: Mediação; 1998.

17 Luckesi CC. Avaliação da aprendizagem escolar: estudos e proposições. São Paulo: Cortez; 1995.

18 Delors J. Educação: Um tesouro a descobrir. $8^{\mathrm{a}}$ ed. São Paulo: Cortez, UNESCO/MEC; 2003.

19 Libâneo JC. Democratização da escola pública: A pedagogia crítico-social dos conteúdos. $20^{\mathrm{a}}$ ed. São Paulo: Edições Loyola; 2005.

20 Buriolla MAF. O estágio supervisionado. $2^{\mathrm{a}}$ ed. São Paulo: Cortez; 1999.

21 Ito EE. O estágio curricular segundo a percepção dos enfermeiros assistenciais de um hospital de ensino [dissertação]. São Paulo (SP): Universidade de São Paulo; 2005. 